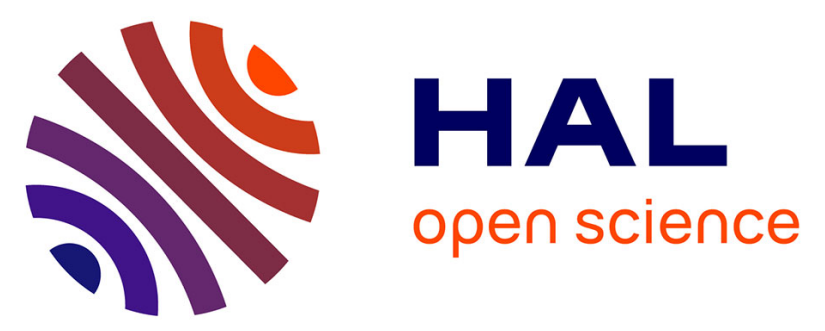

\title{
Betanin-enriched red beetroot (Beta vulgaris L.) extract induces apoptosis and autophagic cell death in MCF-7 cells.
}

Laëtitia Nowacki, Pascale Vigneron, Laura Rotellini, Hélène Cazzola, Franck Merlier, Elise Prost, Robert Ralanairina, Jean-Pierre Gadonna, Claire Rossi,

Muriel Vayssade

\section{To cite this version:}

Laëtitia Nowacki, Pascale Vigneron, Laura Rotellini, Hélène Cazzola, Franck Merlier, et al.. Betaninenriched red beetroot (Beta vulgaris L.) extract induces apoptosis and autophagic cell death in MCF-7 cells.. Phytotherapy Research, 2015, 29, pp.1964-1973. 10.1002/ptr.5491 . hal-03003487

\section{HAL Id: hal-03003487 \\ https://hal.science/hal-03003487}

Submitted on 13 Nov 2020

HAL is a multi-disciplinary open access archive for the deposit and dissemination of scientific research documents, whether they are published or not. The documents may come from teaching and research institutions in France or abroad, or from public or private research centers.
L'archive ouverte pluridisciplinaire HAL, est destinée au dépôt et à la diffusion de documents scientifiques de niveau recherche, publiés ou non, émanant des établissements d'enseignement et de recherche français ou étrangers, des laboratoires publics ou privés. 


\section{Betanin-enriched red beetroot (Beta vulgaris L.) extract induces apoptosis and autophagic cell death in MCF-7 cells}

\section{Short title: In vitro antitumor activity of betacyanins}

Laëtitia Nowacki ${ }^{1,2}$, Pascale Vigneron ${ }^{2}$, Laura Rotellini ${ }^{2}$, Hélène Cazzola ${ }^{1}$, Franck Merlier ${ }^{1}$, Elise Prost ${ }^{1}$, Robert Ralanairina ${ }^{3}$, Jean-Pierre Gadonna ${ }^{3}$, Claire Rossi ${ }^{1 *}$, Muriel Vayssade ${ }^{2 *}$

${ }^{1}$ Sorbonne universités, Université de technologie de Compiègne, CNRS, Unité Génie Enzymatique et Cellulaire, Centre de recherche Royallieu, CS 60319, 60203 Compiègne cedex, France

${ }^{2}$ Sorbonne universités, Université de technologie de Compiègne, CNRS, UMR 7338 Biomécanique et Bioingénierie, Centre de recherche Royallieu, CS 60319, 60203 Compiègne cedex, France

${ }^{3}$ Institut Polytechnique LaSalle Beauvais, département STAI, rue Pierre Waguet, BP 30313, 60026 Beauvais, France

\section{*correspondence:}

Muriel Vayssade, Sorbonne universités, Université de technologie de Compiègne, CNRS, UMR 7338 Biomécanique et Bioingénierie, Centre de recherche Royallieu, CS 60319, 60203 Compiègne cedex, France

Phone : +33 344237309 - E-mail: muriel.vayssade@utc.fr

Claire Rossi, Sorbonne universités, Université de technologie de Compiègne, CNRS, Unité Génie Enzymatique et Cellulaire, Centre de recherche Royallieu, CS 60319, 60203 Compiègne cedex, France

Phone : +33 344234585 - E-mail: claire.rossi@utc.fr 


\section{ABSTRACT}

Recent studies have pointed out the preventive role of beetroot extracts against cancers and their cytotoxic activity on cancer cells. Among many different natural compounds, these extracts contained betanin and its stereoisomer isobetanin which belong to the betalain group of highly bioavailable antioxidants. However, a precise identification of the molecules responsible for this tumor-inhibitory effect was still required. We isolated a betanin/isobetanin concentrate from fresh beetroots, corresponding to the highest purified betanin extract used for studying anticancer activities of these molecules. The cytotoxicity of this betanin-enriched extract was then characterized on cancer and normal cells and we highlighted the death signalling pathways involved. Betanin/isobetanin concentrate significantly decreased cancer cell proliferation and viability. Particularly in MCF-7-treated cells, the expressions of apoptosis-related proteins (Bad, TRAILR4, FAS, p53) were strongly increased and the mitochondrial membrane potential was altered, demonstrating the involvement of both intrinsic and extrinsic apoptotic pathways. Autophagosome vesicles in MCF-7-treated cells were observed, also suggesting autophagic cell death upon betanin/isobetanin treatment. Importantly, the betanin-enriched extract had no obvious effect towards normal cell lines.

Our data bring new insight to consider the betanin/isobetanin mix as therapeutic anticancer compound, alone or in combination with classical chemotherapeutic drugs, especially in functional p53 tumors.

Keywords: betanin concentrate, isobetanin, betalains, anticancer activity, 2D and 3D cultures 


\section{INTRODUCTION}

With surgery and radiotherapy, chemotherapy is a major treatment for cancer. Chemical agents act on cancer cells at different levels and trigger cell destruction via the induction of an apoptotic program. However classic chemotherapeutic agents often target rapidly dividing cancer and normal cells, leading to side effects for the patients (Rao et al., 2013). As the cancer incidence in worldwide tends to increase, the development of new, safer and efficient anticancer agents is a major challenge.

Certain plant-derived compounds exhibit anticancer activities and have attracted interest in preventing and treating cancers with over $60 \%$ of currently used anticancer agents derived from natural sources (Cragg and Newman, 2005; Gupta and Prakash, 2014). Beetroots contain both red (betacyanins) and yellow pigments (betaxanthins) known collectively as betalains, which constitute a class of highly bioavailable natural antioxidant pigments (Kanner et al., 2001; Tesoriere et al., 2004 and 2013). In the red beetroot species, the predominant betacyanins are betanin (Figure 1A), which represents between 75 and $90 \%$ of the total pigments of red beetroot (Henry, 1996), and isobetanin, its C15 stereoisomer. In addition to the powerful antioxidant properties of betalains, studies have pointed out their preventive role against cancers (Kapadia et al., 1996 and 2003; Lechner et al., 2010). Nevertheless these studies were based on animal diet with red food coloring (E162) and other standard beetroot extracts, whose betanin content does not exceed $1.2 \%$. Antitumoral activity of betalains was also evaluated in vitro on several cancer cell lines, but data obtained by the authors were disparate according to the cell lines and the cytotoxicity assays used (Reddy et al., 2005; Sreekanth et al., 2007; Paluszczak et al., 2010). Moreover, the betanin content or the 
purity degree of beetroot extracts used have never been precisely defined. In order to dispel any ambiguity, the characterization of the betanin effect on tumor cells requires a highly purified betanin concentrate with a precisely known composition.

During preclinical testing, in vitro analyses are performed to select compounds with potential antitumor activity before in vivo studies in relevant animal models. Cell culture approach is therefore of the highest importance for the initial screening of molecules. However cell lines used are conventionally cultured as monolayers (2D culture) and do not mimic the phenotype of cancer tissues due to the lack of cell-cell and cell-extracellular matrix interactions. 3D models (cell spheroids or aggregates) are obtained by preventing cells from attaching to the culture substrata. Based on their ability to mimic tissue-like structures more effectively than $2 \mathrm{D}$ cell cultures, the use of 3D in vitro models is believed to be a requisite mean into anticancer drug development (Breslin and O’Driscoll, 2013).

This study was carried out to clarify the antitumor effect of a betanin-enriched beetroot dried extract. We used both $2 \mathrm{D}$ and $3 \mathrm{D}$ cultures to assess the cytotoxic activity of betanin on cancer and normal cells. Our results showed that the betanin concentrate induces cancer cell growth inhibition, associated with an apoptotic cell death and an autophagic activity increase in MCF-7 cells, but has no obvious effect towards normal cells. 


\section{MATERIALS AND METHODS}

\section{Betanin extraction and purification}

Grinded red beetroots (local market) were extracted into ethanol/water (80/20 v/v) solvent at a solid/liquid ratio of $1 / 3(\mathrm{~g} / \mathrm{mL})$ for $1 \mathrm{~h}$ under continuous mechanical stirring. The solid material was separated from the macerate by centrifugation at $12000 \mathrm{~g}$ for 15 min at $4{ }^{\circ} \mathrm{C}$ followed by a filtration on a polypropylene membrane filter $(0.2 \mu \mathrm{m}$, Pall Corporation). The filtrate was concentrated by ethanol evaporation under reduced pressure at $30^{\circ} \mathrm{C}$ and then enriched in betanin and isobetanin by adsorption chromatography (Stintzing et al., 2002). A glass column was packed with 1 L of activated polymeric adsorbent (Amberlite XAD-16, Sigma-Aldrich, France). The $\mathrm{pH}$ of beetroot extract was adjusted to 3 with hydrochloric acid $(\mathrm{HCl}) .100 \mathrm{~mL}$ of extract was passed through the resin column at 1 Bed Volume (BV) per hour. After adsorption of the betacyanins, the other extract constituents were eluted using $3 \mathrm{BV}$ of deionized water (resistivity $>18.2 \mathrm{~m} \Omega . \mathrm{cm}^{-1}$, MilliQ plus unit, Merk-Millipore) acidified to $\mathrm{pH} 3$ at $2 \mathrm{BV} / \mathrm{h}$. Betanin and isobetanin were eluted with ethanol at $0.5 \mathrm{BV} / \mathrm{h}$. The collected fraction was concentrated by ethanol evaporation under vacuum at $30^{\circ} \mathrm{C}$ and freezedried. The obtained betanin/isobetanin-enriched powder was stored at $-80^{\circ} \mathrm{C}$.

\section{Extract characterization}

Betanin quantification. All betacyanin/betaxanthin quantifications were performed using the multi-component photometric method described by J.H. von Elbe (von Elbe et $a l ., 2001)$. The pigment concentration calculations were based upon the absorptivity 
values: $\mathrm{A}^{1 \%} 1120$ for betanin and isobetanin (at $538 \mathrm{~nm}$ ) and 750 for betaxanthins (at $477 \mathrm{~nm})$.

Protein and total carbohydrate quantifications. Total carbohydrate amount present in extracts was determined using the DuBois method (DuBois et al., 1956). Glucose was used as a standard. The protein quantification was performed using the Lowry method (Lowry et al., 1951). The absence of pigment inferences with these two colorimetric methods was controlled.

HPLC/ESI-MS analysis. The HPLC system (Infinity 1290, Agilent Technologies, France) was equipped with diode array detector coupled with a Q-TOF micro hybrid quadrupole time of flight mass spectrometer (Agilent 6538, Agilent technologies, France). HLPC analyses were performed using an analytical scale (150 mm x $2.1 \mathrm{~mm}$ i.d.) hypersil gold C18 reversed phase column with a particle size of $3 \mu \mathrm{m}$ (Thermo Scientific, France). Eluents A and B (LC-MS grade) consisted of 100\% water with 0.2 $\%$ (v/v) formic acid and $100 \%$ acetonitrile respectively. Betalains separation was achieved within $40 \mathrm{~min}$ at $20^{\circ} \mathrm{C}$ at a flow rate of $0.3 \mathrm{~mL} / \mathrm{min}$. The elution profile was: 0 3 min $100 \%$ A, 3-21 min 0-13\% B in A (linear gradient), 21-24 min 13\% B, 24-30 min 13-50\% B (linear gradient), 30-33 min 50-100\% B, 33-40 min $100 \%$ B. Detection wavelengths were $477 \mathrm{~nm}$ (betaxanthins and betacyanins) and $538 \mathrm{~nm}$ (betacyanins only). Positive ion electrospray mass spectra were acquired by scan mode, consisted of scanning from m/z 50 to 1700 at electrospray voltage $3800 \mathrm{~V}$, fragmentor voltage 140 V. Nitrogen was nebulized at $12.0 \mathrm{~L} / \mathrm{min}$ under $45.0 \mathrm{psi}$ and heated at $350^{\circ} \mathrm{C}$. Betanin and isobetanin structural identities were confirmed by tandem mass (relative collision energy of $15 \mathrm{eV}$ ) spectroscopy and NMR studies. The ${ }^{1} \mathrm{H}$ NMR spectrum of betanin was 
recorded in $\mathrm{D}_{2} \mathrm{O}$ (data not shown) and corresponds to the previously published data (Stinzting et al., 2004).

\section{Cell culture and treatment}

The mouse melanoma cell line B16F10 was a generous gift from Dr L. Larue (Institut Curie, France). Human breast cancer lines (MCF-7 ATCC ${ }^{\circledR}$ HTB-22, MDA-MB-231 ATCC ${ }^{\circledR}$ HTB-26), human colorectal cells (HT-29 ATCC ${ }^{\circledR}$ HTB-38) and normal human fibroblasts (MRC-5 ATCC ${ }^{\circledR}$ CCL-171) were obtained from the American Type Culture Collection. Human umbilical vein endothelial cells (HUVEC) were purchased from PromoCell.

Cells were cultured as monolayers in RPMI 1640 (B16F10), MEM (MCF-7, MDA-MB231, MRC-5), DMEM (HT-29) or M199 (HUVEC). All cell culture media (Gibco, Invitrogen, France) were supplemented with $10 \%$ fetal bovine serum (FBS, Gibco, Invitrogen), $2 \mathrm{mM}$ L-glutamine (Gibco, Invitrogen), penicillin (100 $\mu \mathrm{g} / \mathrm{mL}$, Gibco, Invitrogen) and streptomycin (100 $\mu \mathrm{g} / \mathrm{mL}$, Gibco, Invitrogen). All cell lines were maintained at $37^{\circ} \mathrm{C}$ in an air atmosphere of $10 \% \mathrm{CO}_{2}(\mathrm{~B} 16 \mathrm{~F} 10)$ or $5 \% \mathrm{CO}_{2}(\mathrm{MCF}-7$, MDA-MB-231, HT-29, HUVEC, MRC-5).

Nunclon ${ }^{\circledR}$ polystyrene plates (tPS) were used for 2D cultures. Polyhydroxyethylmethacrylate (polyHEMA, Sigma Aldrich) coated polystyrene plates were prepared as previously described (Velzenberger et al., 2008) and used for 3D cultures. Cells were seeded at 10000 cells $/ \mathrm{cm}^{2}$ without (controls) or with increasing concentrations of betanin/isobetanin (from 10 to $40 \mu \mathrm{M}$ ), and cultured for 24 or 48 hours. 


\section{Proliferation assay and cell cycle analysis}

In $2 \mathrm{D}$ cultures, cells were removed by incubation for $5 \mathrm{~min}$ at $37^{\circ} \mathrm{C}$ in $0.25 \%$ trypsin +1 mM EDTA solution (Gibco, Invitrogen). In 3D cultures, aggregates were collected by centrifugation (5 min, 200g) and dissociated using trypsin-EDTA solution. Trypsin reaction was stopped by adding half a volume of FBS, and cells were counted in a Malassez hemocytometer using trypan blue exclusion assay. The proliferative index was estimated as the ratio between viable cell counts 48 hour post-seeding and number of seeded cells. Each proliferative index was normalized to this one obtained for control cells and data were expressed as percentages.

For cell cycle analysis, harvested cells were washed twice in PBS containing $5 \mathrm{mM}$ EDTA, and fixed for 45 min at $4^{\circ} \mathrm{C}$ in $1 \mathrm{~mL} 75 \%$ ethanol in PBS with $5 \mathrm{mM}$ EDTA. Cell lines were washed twice and suspended in PBS, $5 \mathrm{mM}$ EDTA containing $0.1 \%$ TritonX100 (Sigma Aldrich) mixed with $40 \mu \mathrm{g}$ RNase A (Sigma Aldrich) and $25 \mu \mathrm{g}$ propidium iodide (PI, Sigma Aldrich) and incubated for 15 min protected from light. The stained samples were analysed in Gallios flow cytometer (Beckman Coulter, France). Histograms were analysed using Wincycle software (PHOENIX flow systems, USA).

\section{Apoptosis detection and quantification}

To assess early stage of apoptosis, cells cultured in 2D and 3D conditions were treated with $30 \mu \mathrm{M}$ betanin/isobetanin mix for 24 hours and labeled with Annexin-V-FITC (Beckman Coulter). For each cell line, a positive control for apoptosis was tested (cells treated with $1 \mu \mathrm{M}$ staurosporine). The cytometer was adjusted according to the Annexin-V positive cells of these controls. According to the manufacturer's 
instructions, cells were washed with PBS and suspended in the binding buffer at $5.10^{5}$ to $5.10^{6}$ cells $/ \mathrm{mL} .1 \mu \mathrm{L}$ of Annexin-V FITC solution and $5 \mu \mathrm{L}$ of PI solution were added to $100 \mu \mathrm{L}$ of cell suspension. Cells were incubated for $15 \mathrm{~min}$ on ice in the dark, and then diluted by adding $400 \mu \mathrm{L}$ of binding solution. The Annexin-V positive/IP negative cell populations were detected with a Gallios flow cytometer and were representative of apoptotic cells.

To detect DNA fragmentation, an Apostain binding assay (AbCys) was used. MCF-7 and HUVEC cells were treated with betanin/isobetanin $(30 \mu \mathrm{M})$ or staurosporine $(1$ $\mu \mathrm{M})$ for 48 hours, fixed with ice-cold methanol $80 \%(\mathrm{v} / \mathrm{v})$ for $30 \mathrm{~min}$, washed and suspended in $250 \mu \mathrm{L}$ formamide for $10 \mathrm{~min}$ at $75^{\circ} \mathrm{C}$ and for $5 \mathrm{~min}$ at room temperature (RT). Cells were then incubated for $45 \mathrm{~min}$ at RT with a mouse monoclonal antibody to single-stranded DNA (ssDNA, diluted 1:10 in PBS containing 5\% FBS). Bound specific antibodies were revealed by incubation with Cy3-conjugated anti-mouse antibody (diluted 1:200 in PBS containing 1\% milk, Jackson ImmunoResearch) for $30 \mathrm{~min}$ at RT. Each sample was counterstained with DAPI (4',6'-diamidino-2-phénylindole, $1 \mu \mathrm{g} / \mathrm{mL}$, Sigma-Aldrich). The cells were then cytocentrifuged (Shandon Cytospin®) and each slide was mounted in mowiol and examined by epifluorescence microscopy (Leica DMI6000). Ten fields were randomly chosen from each slide and the percentage of apoptotic cells in each picture was calculated as the ratio of the labeling cells to the total number of cells.

\section{Apoptotic signaling pathway analysis}

Human Apoptosis arrays (Proteome Profiler ${ }^{\mathrm{TM}}$ Array, R\&D Systems) were used to simultaneously detect the relative levels of expression of 35 apoptosis-related proteins. 
MCF-7, MDA-MB-231 and HUVEC cells were treated with betanin/isobetaninenriched extract for 48 hours, rinsed with PBS and lysed for 30 min at $4{ }^{\circ} \mathrm{C}$ using lysis buffer provided by the manufacturer. Lysates were then centrifuged at $14000 \mathrm{~g}$ for 5 min and supernatants were harvested. Protein concentrations for each sample were determined using the Bradford method (Coomassie Protein Assay Reagent, Pierce, Interchim). $400 \mu \mathrm{g}$ of cell lysates were incubated on each array overnight at $4^{\circ} \mathrm{C}$. Arrays were incubated for $1 \mathrm{~h}$ at $\mathrm{RT}$ with a reconstituted detection antibody cocktail, and then with a streptavidin-HRP solution for $30 \mathrm{~min}$. Arrays were revealed with a Chemireagent Mix using ChemiDoc (Biorad), and each spot was quantified with Quantity One software (Biorad).

To detect change in the mitochondrial membrane potential, a MitoCapture ${ }^{\mathrm{TM}}$ dye (BioVision) was used. MCF-7 cells were treated with betanin/isobetanin mix (15 and 30 $\mu \mathrm{M})$ for 24 hours, harvested and then resuspended in $1 \mathrm{~mL}$ diluted MitoCapture ${ }^{\mathrm{TM}}$ reagent provided by the manufacturer. Cells were incubated for $20 \mathrm{~min}$ at $37^{\circ} \mathrm{C}$ in a $5 \%$ $\mathrm{CO}_{2}$ incubator. After centrifugation $(500 \mathrm{~g})$, the supernatant was discarded, the cells were suspended in $1 \mathrm{~mL}$ of pre-warmed incubation buffer and analyzed by epifluorescence microscopy.

\section{Autophagy assay}

Autophagy was detected using the Autophagy Detection Kit (Abcam). Briefly, MCF-7 cells were grown 24 hours on glass slides, and then were treated with betanin/isobetanin (15 and $30 \mu \mathrm{M})$ or with an autophagy inducer, rapamycin (500 $\mathrm{nM}$ provided by the manufacturer) for 24 hours. Medium was removed and cells were washed with a buffer supplied by the manufacturer. Cells were incubated with the dye (diluted at 1:500 in 
assay buffer) and DAPI for $20 \mathrm{~min}$ at $37^{\circ} \mathrm{C}$. Cells were carefully washed and slides were examined by epifluorescence microscopy.

\section{Statistical analysis}

All statistical evaluations were performed using GraphPad InStat software. Continuous variables are expressed as means \pm standard deviation. As most of the continuous values measured had a non-Gaussian distribution, non-parametric Dunn and Kruskal-Wallis tests were used for comparisons. A value of $\mathrm{p}<0.05$ was taken as significant.

\section{RESULTS}

\section{Betanin/isobetanin concentrate characterization}

Figure 1B shows the chromatogram corresponding to the pigment-enriched red beetroot dried extract obtained after purification by adsorption chromatography. The HPLC profile monitored at $477 \mathrm{~nm}$ combined with electrospray mass spectrometry in positive mode allows the identification of the betaxanthin and betacyanin molecules contained in this final extract (Stintzing et al., 2004). Only two betalains were detected and identified as betanin $\left(t_{R}=13.05 \min ,[M+H]^{+}=551\right)$ and isobetanin, the $15 \mathrm{R}$ stereoisomer of betanin $\left(\mathrm{t}_{\mathrm{R}}=14,51 \mathrm{~min},[\mathrm{M}+\mathrm{H}]^{+}=551\right)($ Kujala et al., 2002; Stintzing et al., 2004). The betanin and isobetanin structures were confirmed by mass tandem spectroscopy. The

positive ion spray mass spectrum (Figure 1C) shows the daughter ion produced by fragmentation of the parent ion of $\mathrm{m} / \mathrm{z}$ of $551[\mathrm{M}+\mathrm{H}]^{+}=551$ assigned to betanin or isobetanin. The fragment ion at the mass charge $(\mathrm{m} / \mathrm{z})$ of 389 indicated that this ion is 
obtained by glucose loss and corresponds to the protonated aglycones [betanidin $+\mathrm{H}]^{+}$ or [isobetanidin $+\mathrm{H}]^{+}$(Castellanos-Santiago and Yahia, 2008).

All the betaxanthins were eluted during beetroot extract purification on polymeric resin while the betacyanins remained absorbed. Total carbohydrate quantification reveals that they are totally eliminated at this purification step, no residual complex or simple carbohydrates could be detected in the final betanin concentrate. As betanin and isobetanin differ only by the absolute configuration of their $\mathrm{C} 15$ chiral center, we did not distinguish them for determination of the total pigment amount in the purified extract. The total betanin/isobetanin content in the dried concentration was evaluated at $80 \%$ by photometric quantification. The remaining $20 \%$ was attributed to residual proteins by total protein content determination. Based on HPLC peak area values, the betacyanin composition was estimated at $64 \%$ of betanin and $36 \%$ of isobetanin. In the rest of the article, all the concentrations given correspond to the total betanin/isobetanin (Bet./IsoBet.) concentrations applied to the cells.

\section{Effect of betanin/isobetanin on cell proliferation and morphology}

We used both cancer (B16F10, MCF-7, MDA-MB-231, HT-29) and normal (HUVEC, MRC-5) cells to assess the biological effect of betanin extract. All cells were cultured as monolayer (2D) on tPS and as aggregates (3D) on anti-adhesive polyHEMA substratum, and then treated with betanin-enriched extract for 48 hours.

As shown in Figure 2A, Bet./IsoBet. treatment significantly decreased the proliferation of B16F10 and MCF-7 cells on both surfaces. The half maximal inhibitory concentration (IC50) was determined for each cell lines, and was about $25 \mu \mathrm{M}$ for B16F10 and MCF-7 cells. No viable cells were observed with $40 \mu \mathrm{M}$ Bet./IsoBet. (data 
not shown). MDA-MB-231 and HUVEC cells were also sensitive to betanin-enriched extract, but to a lower extent (IC50 value was $35 \mu \mathrm{M}$ ) (Figure 2B). The cell viabilities measured 48 hour post-treatment with $40 \mu \mathrm{M}$ Bet./IsoBet. decreased weakly: $35.6 \% \pm$ $17.2(2 \mathrm{D})$ and $52.0 \% \pm 19.2(3 \mathrm{D})$ for MDA-MB-231 and $75.2 \% \pm 26.9(2 \mathrm{D})$ and $71.0 \%$ \pm 27.4 (3D) for HUVEC cells (data not shown). For the same concentration range, HT29 and MRC-5 cells were not sensitive to betanin concentrate: at $40 \mu \mathrm{M}$, cell proliferation was not significantly decreased compared to controls (Figure 2C). Viabilities of HT-29 cells treated with $40 \mu \mathrm{M}$ Bet./IsoBet. for 48 hours were $95.2 \% \pm$ 5.3 (2D) and 96.6\% \pm 5.2 (3D) (data not shown). For MRC-5 cells, viabilities remained high with betanin/isobetanin treatment: $87.7 \% \pm 9.3(2 \mathrm{D})$ and $76.8 \% \pm 12.8(3 \mathrm{D})$.

Cell morphologies were examined (Figure 2D): MCF-7 and HUVEC control cells cultured on tPS spread well and colonized the culture dishes, while cells on polyHEMA had a rounded aggregated morphology. Betanin-enriched extract reduced MCF-7 cell spreading on tPS and MCF-7 cell aggregation on polyHEMA, whereas a moderate effect of betanin/isobetanin concentrate was observed on HUVEC cells cultured in 2D and 3D conditions. No morphological change was observed for the HT-29 and MRC-5 cells treated with Bet.IsoBet. (data not shown).

Thus we identified three groups of cell lines with different sensitivities to betanin/isobetanin: B16F10 and MCF-7 as highly sensitive (no viable cells with $40 \mu \mathrm{M}$ Bet./IsoBet.); MDA-MB-231 and HUVEC as weakly sensitive (cell viabilities from $35 \%$ to $70 \%$ with $40 \mu \mathrm{M}$ Bet./IsoBet.); HT-29 and MRC-5 as resistant (cell viabilities about $90 \%$ with $40 \mu \mathrm{M}$ Bet./IsoBet.). 


\section{Effect of betanin/isobetanin concentrate on cell cycle distribution}

To better understand betanin/isobetanin concentrate effect, we focused on three human cell lines that represent three different and specific phenotypes: p53 wild-type cancer cell line MCF-7, p53-mutated cancer cell line MDA-MB-231 and normal HUVEC cells.

The cell cycle progression was studied 48 hour post-seeding without (control) or with $30 \mu \mathrm{M}$ Bet./IsoBet. (Table 1). For each cell line, the cell cycles of control cultures on tPS and polyHEMA were significantly different: there were more cells in G1 phase and fewer in the $\mathrm{S}$ and $\mathrm{G} 2 / \mathrm{M}$ phases in 3D cultures.

Betanin/isobetanin-enriched extract significantly decreased the percentage of MCF-7 cells in G1 phase (2D and 3D conditions) and increased percentage of cells in S phase (2D culture) or G2/M phase (3D culture). For MDA-MB-231 and HUVEC cell lines, betanin/isobetanin concentrate decreased cell number in $S$ phase (2D). No obvious effect of Bet./IsoBet. was observed on the 3D MDA-MB-231 cell cycle repartition. Betanin/isobetanin treatment decreased the 3D HUVEC cell number in G1 phase and increased the percentage of cells in S and G2/M phases.

\section{Characterization of MCF-7 cell death induced by betanin/isobetanin concentrate}

As MCF-7 cell viabilities strongly decreased during Bet./IsoBet. treatment, we analyzed the nature of cell death induced by the pigments. First we checked apoptosis induction and quantification using Annexin-V-FITC labeling and cell analysis by flow cytometry (Table 2, Figure 3A). Our results showed that betanin/isobetanin treatment significantly increased the percentage of Annexin-V positive/PI negative MCF-7 cells, as the positive control staurosporine. MCF-7 3D cell culture promoted phosphatidylserine externalization, and the percentage of Annexin- $\mathrm{V}$ positive cells was found to be 
increased with betanin/isobetanin or staurosporine. MDA-MB-231 cells cultured in 2D or 3D with Bet./IsoBet. were not strongly labeled with Annexin-V-FITC probe (Table 2). Interestingly, HUVEC cells were found to be non-apoptotic when cultured in $2 \mathrm{D}$ and treated with Bet./IsoBet., whereas staurosporine treatment induced significantly apoptosis (Table 2, Figure 3A). Anchorage-independent culture of HUVEC cells triggered Annexin-V labeling and the percentage of apoptotic cells was slightly increased with betanin/isobetanin treatment. To confirm apoptosis induction in MCF-7 cells treated with betanin/isobetanin concentrate, we analyzed DNA fragmentation using an antibody recognizing single-stranded DNA. After culture for 48 hours with betanin/isobetanin $(30 \mu \mathrm{M})$ or staurosporine $(1 \mu \mathrm{M})$, about $80 \%$ of MCF-7 cells were labelled (Figure 3B). Only $1.84 \%$ of HUVEC cells treated with betanin-enriched extract were found to be positive (Figure 3B), whereas $29.03 \%$ were labeled with the positive control staurosporine.

Proteome profiler arrays allowed us to detect the expression levels of apoptosis-related proteins in MCF-7, MDA-MB-231 and HUVEC cells treated with $30 \mu \mathrm{M}$ Bet./IsoBet. Typical results of obtained arrays are shown in Figure 4A. The most important differences in protein expressions were found in sensitive MCF-7 cells: we observed a strong induction of Bad, TRAILR1/DR4, Fas/TNFRSF6/CD95 and phospho-p53 (S392) proteins in betanin-treated cells compared to control cells (Figure 4B, Table I supplementary data). No significant variation in protein expression was observed in MDA-MB-231 cells. In HUVEC cells, Bet./IsoBet. treatment induced a moderate overexpression of p21 and p27 proteins (Table I supplementary data).

The effect of betanin/isobetanin on the mitochondrial membrane potential was checked in MCF-7 cells using MitoCapture dye (Figure 5). Our data showed an increase in green 
fluorescence in betanin/isobetanin-treated cells, in a same extent than positive control (curcumin $50 \mu \mathrm{M}$ ).

To assess another cell death, autophagy, MCF-7 cells treated with Bet./IsoBet. or rapamycin (an autophagy inducer) were analyzed for lysosomal vacuole formation (Figure 6). We observed positive labeling in MCF-7-treated cells, indicating an autophagic activity increase.

\section{DISCUSSION}

We described that a highly betanin/isobetanin-enriched concentrate produced from red beetroots inhibits cancer cell proliferation and induces MCF-7 cell death, but has no obvious effect towards normal cells.

Betanin and isobetanin are the most predominant betalains in red beetroot. We were able to obtain a pigment-enriched dried extract from beetroots which contains only betanin/isobetanin as coloring agents. This concentrate consists of $80 \%$ of betanin/isobetanin mixture (of which betanin accounts for $64 \%$ and isobetanin for $36 \%$ ) and corresponds, to our knowledge, to the highest purified betanin extract used for studying its anticancer activities. To better evaluate the cytotoxicity of the betaninenriched extract, we used two different culture conditions: classical monolayer culture (2D) and cells cultured as aggregates on anti-adhesive substratum (3D) (Velzenberger $e t$ $a l ., 2008)$. These 3D culture models are now commonly used to study new anticancer agents because they are believed to bridge the gap between in vitro $2 \mathrm{D}$ assessment and animal models (Breslin and O'Driscoll, 2013). Cell cytotoxicity analysis revealed that p53 wild-type cancer cell lines (B16F10, MCF-7) were highly sensitive to $40 \mu \mathrm{M}$ 
betanin/isobetanin mix (assessed by proliferation inhibition and low cell viabilities), whereas cancer cell lines expressing mutated p53 were less (MDA-MB-231) or not sensitive (HT-29) for the same concentration range. The betanin-enriched extract effect was similar whatever the culture conditions, 2D or 3D. This shows that betanin/isobetanin concentrate inhibits aggregated cancer cell proliferation, a cell structure known as more resistant to apoptosis induction (Hirschhaeuser et al., 2010). In this way, B16F10 and MDA-MB-231 are metastatic cell lines, resistant to anoikis when cultured under anchorage-independent conditions because of the activated ERK signaling pathway (Goundiam et al., 2010; Fukazawa et al., 2002). For these reasons, identifying an efficient molecule on anoikis resistant cancer cells is a very hopefully result. Cell proliferation inhibition by betanin/isobetanin was confirmed with affected cell cycle. In MCF-7 cells, betanin/isobetanin extract decreased the G1 and G2/M cell number and promoted S phase increase, a behavior previously described when MCF-7 cells were treated with cell growth inhibitors as resveratrol and riproximin (Joe et al., 2002; Pervaiz et al., 2015). Betanin/isobetanin extract may downregulate the expression of cell cycle regulators (cyclin B1, cyclin A2) resulting in G2 phase entry inhibition and S phase arrest, as act resveratrol and riproximin. 2D cultured MDA-MB-231 cells were blocked in G1 phase during treatment, but the molecules did not significantly affect the cell cycle repartition when cells were cultured as aggregates, probably because of the G1 arrest induced by the culture configuration.

Kapadia et al. (2011 and 2013) have previously evaluated the cytotoxic effect of a red beetroot extract in MCF-7 cell line and the IC50 value they obtained was $600 \mu \mathrm{M}$ (after 72 hours of exposure). Reddy et al. (2005) also observed a growth inhibition of MCF-7 cells treated with a betanin concentrate for 48 hours (IC50 value was $294 \mu$ M). Our data 
clarify these previous studies. The betanin purification process we applied to the crude beetroot extract, allowed us to obtain a significant MCF-7 growth inhibition associated with cell death for very low concentrations (below $40 \mu \mathrm{M}$ ).

As MCF-7 cell viability strongly decreased when treated with betanin/isobetanin mix, the nature of cell death was analyzed. Using different methods, we showed that betanin treatment induced apoptosis in 2D MCF-7 cells. The expressions of apoptosis-related proteins (Bad, TRAILR4, FAS, phosphorylated p53) were strongly increased and the mitochondrial membrane potential was clearly altered. Taken together, all these data suggest both mitochondrial and death-receptor pathway involvement, and a p53dependent response in MCF-7 cells treated with the betanin/isobetanin concentrate. Betanin extract $(30 \mu \mathrm{M})$ only induced a moderate apoptosis in aggregated MCF-7 cells, a 3D configuration often promoting cell death resistance. Recently, Gong et al. (2015) have compared the cytotoxicity effect of the doxorubicin on MCF-7 cells cultured as monolayer or spheroids. Their data show that 3D cultured MCF-7 cells were less sensitive than their 2D counterpart. According to our data on cell proliferation and viability, we would probably observe an apoptosis induction on 3D MCF-7 cells with higher concentrations of betanin/isobetanin mix.

Intrinsic pathway activation upon betanin exposure was previously observed by Sreekanth et al. (2007) in K562 cells with mitochondrial membrane potential decrease and cytochrome c release. A significant activation of caspase 9 and effectors (caspases 3 and 7) was also reported in lung cancer cells treated with $400 \mu \mathrm{M}$ betanin for 48 hours (Zhang et al., 2013). Our results confirm these previous studies about the mitochondrial pathway involvement. Moreover, we show that betanin/isobetanin mix induces upregulation of death receptors and p53 activation, as curcumin does on MCF-7 cells 
(Choudhuri et al., 2002; Mohankumar et al., 2014). P53 is a well-known important actor in response to cellular stresses (Goh et al., 2011). The mutated p53 status in MDA-MB-231 and HT-29 cells (Bartek et al., 1990; Rodrigues et al., 1990) could explain in part the weak betanin cytotoxicity for these cell lines. Particularly, HT-29 cells express a mutant p53 protein which gains function, promoting cell proliferation and chemoresistance (van Oijen and Slootweg, 2000). In this way, Arafa et al. (2013) have recently compared HT-29 and MDA-MB-231 sensitivity to novel quinoline-based compounds. They found that the HT-29 cell line was more refractory to the cytotoxic activity of most compounds than MDA-MB-231 cells. In our work, HT-29 cells were also resistant to betanin/isobetanin effect, whereas molecules slowed down MDA-MB231 cell proliferation without inducing apoptosis. Therefore low concentrations of betanin-enriched extract appear to be efficient on a wild-type p53 cancer cells to induce cell death (MCF-7) and inhibit a p53-mutated cancer cell proliferation (MDA-MB-231), but have no effect on another p53-mutated cell line (HT-29).

As some natural-derived compounds have already been shown to induce cell death via an autophagic process (Zhang et al., 2012), we investigated and revealed lysosomal vacuole formation in MCF-7 cells upon betanin treatment. We are the first to describe that betanin/isobetanin mix also induces an autophagic response in cells. The identification of molecules that target autophagy is believed to be a realistic prospect for cancer therapy (Bincoletto et al., 2013).

To fully characterize the biological effect of betanin, we also evaluated its cytotoxicity on normal cells. Importantly, normal cell lines (HUVEC, MRC-5) were found to be weakly or not sensitive to betanin $\mathrm{C} 15$ stereoisomer mix for the same concentration range used on cancer cells. Particularly, HUVEC endothelial cells slowed down their 
proliferation rate upon betanin exposure, remaining viable for higher concentrations than MCF-7 cells. When cultured as monolayer and treated with the betanin/isobetanin extract, HUVEC cells accumulated in the G1 phase and the percentage of cells in the DNA replicative phase decreased, confirming the cell proliferation data. 3D betanin treated-HUVEC cells progressively accumulated in the $\mathrm{S}$ and G2/M phases. Moreover the betanin/isobetanin treatment triggered an overexpression of $\mathrm{p} 21$ and p27 proteins, cyclin-dependent kinase inhibitors involved in cell cycle arrest. However, the HUVEC cell proliferation inhibition by the betanin concentrate was not associated with apoptosis or autophagy induction: this suggests that undesired side effects could be limited in therapies integrating these molecules. Indeed, the preliminary data we performed on the non-tumorigenic MCF-12F cell line confirmed the harmless interaction of the molecules on normal epithelial breast cells (data not shown).

In conclusion, we reported that a purified betanin/isobetanin concentrate produced from red beetroots is cytotoxic at low concentrations for cancer cells expressing functional p53, but have no or moderate effect on normal cells, suggesting limited in vivo side effects. In p53 wild-type cancer cells, betanin/isobetanin extract induces apoptosis (via extrinsic and intrinsic activation pathways) and autophagy. Moreover, betanin-enriched extract inhibits some p53 mutated cancer cell growth, without inducing apoptosis. Our data bring new insight to consider betanin/isobetanin as therapeutic anticancer molecules alone or in combination with classical chemotherapeutic drugs, especially in functional p53 tumors. 


\section{Acknowledgments}

We thank the European Union (co-funding of equipment within the CPER 2007-2013 and FEDER) and the Conseil Régional of Picardie for financial support (BetOX project).

\section{References}

Arafa RK, Hegazy GH, Piazza GA, Abadi AH. 2013. Synthesis and in vitro antiproliferative effect of novel quinoline-based potential anticancer agents. Eur J Med Chem 63:826-832.

Bartek J, Iggo R, Gannon J, Lane DP. 1990. Genetic and immunochemical analysis of mutant p53 in human breast cancer cell lines. Oncogene 5:893-899.

Bincoletto C, Bechara A, Pereira GJ, Santos CP, Antunes F, Peixoto da-Silva J, Muler M, Gigli RD, Monteforte PT, Hirata H, Jurkiewicz A, Smaili SS. 2013. Interplay between apoptosis and autophagy, a challenging puzzle: new perspectives on antitumor chemotherapies. Chem Biol Interact 206:279-288.

Breslin S and O'Driscoll L. 2013. Three-dimensional cell culture: the missing link in drug discovery. Drug Discov Today 18:240-249. 
Castellanos-Santiago E, Yahia EM. 2008. Identification and quantification of betalains from the fruits of 10 mexican prickly pear cultivars by high-performance liquid chromatography and electrospray ionization mass spectrometry. J Agric Chem 56:57585764.

Choudhuri T, Pal S, Agwarwal ML, Das T, Sa G. 2002. Curcumin induces apoptosis in human breast cancer cells through p53-dependent Bax induction. FEBS Lett 512:334340.

Cragg $G$ and Newman DJ. 2005. Plants as a source of anti-cancer agents. $J$ Ethnopharmacol 100:72-79.

DuBois M, Gilles KA, Hamilton JK, Rebers PA, Smith F.1956. Colorimetric method for determination of sugars and related substances. Anal Chem 28:350-356.

Fukazawa H, Noguchi K, Murakami Y, Uehara Y. 2002. Mitogen-activated protein/extracellular signal-regulated kinase kinase (MEK) inhibitors restore anoikis sensitivity in human breast cancer cell lines with a constitutively activated extracellularregulated kinase (ERK) pathway. Mol Cancer Ther 1:303-309.

Goh AM, Coffill CR, Lane DP. 2011. The role of mutant p53 in human cancer. J Pathol 223:116-126. 
Gong X, Lin C, Cheng J, Su J, Zhao H, Liu T, Wen X, Zhao P. 2015. Generation of multicellular tumor spheroids with microwell-based agarose scaffolds for drug testing. PLoS One 19;10(6):e0130348. doi: 10.1371/journal.pone.0130348.

Goundiam O, Nagel MD, Vayssade M. 2010. Growth and survival signalling in B16F10 melanoma cells in 3D culture. Cell Biol Int 34:385-391.

Gupta C and Prakash D. 2014. Phytonutrients as therapeutic agents. J Complement Integr Med 11:151-169.

Henry BS. 1996. Natural Food Colours. In Natural Food Colorants; Hendry GA, Houghton J. Eds.; Chapman \& Hall: London, UK;40-79.

Hirschhaeuser F, Menne H, Dittfeld C, West J, Mueller-Klieser W, Kunz-Schughart LA. 2010. Multicellular tumor spheroids: an underestimated tool is catching up again. $J$ Biotechnol 148:3-15.

Joe AK, Liu H, Suzui M, Vural ME, Xiao D, Weinstein IB. 2002. Resveratrol induces growth inhibition, S-phase arrest, apoptosis, and changes in biomarker expression in several human cancer cell lines. Clin Cancer Res 8:893-903.

Kanner J, Harel S, Granit R. 2001. Betalains-a new class of dietary cationized antioxidants. J Agric Food Chem 49:5178-5185. 
Kapadia GJ, Tokuda H, Konoshima T, Nishino H. 1996. Chemoprevention of lung and skin cancer by Beta vulgaris (beet) root extract. Cancer Lett 100:211-214.

Kapadia GJ, Azuine MA, Sridhar R, Okuda Y, Tsuruta A, Ichiishi E, Mukainake T, Takasaki M, Konoshima T, Nishino H, Tokuda H. 2003. Chemoprevention of DMBAinduced UV-B promoted, NOR-1-induced TPA promoted skin carcinogenesis, and DEN-induced phenobarbital promoted liver tumors in mice by extract of beetroot. Pharmacol Res 47:141-148.

Kapadia GJ, Azuine MA, Rao GS, Arai T, Iida A, Tokuda H. 2011. Cytotoxic effect of the red beetroot (Beta vulgaris L.) extract compared to doxorubicin (Adriamycin) in the human prostate (PC-3) and breast (MCF-7) cancer cell lines. Anticancer Agents Med Chem 11:280-284.

Kapadia GJ, Rao GS, Ramachandran C, Iida A, Suzuki N, Tokuda H. 2013. Synergistic cytotoxicity of red beetroot (Beta vulgaris L.) extract with doxorubicin in human pancreatic, breast and prostate cancer cell lines. J Complement Integr Med 10:1-10.

Kujala TS, Vienola MS, Klika KD, Lopokonen JM, Pihlaja K. 2002. Betalain and phenolics composition of four beetroot (Beta vulgaris) cultivars. Eur Food Res Technol 214:505-510.

Lechner JF, Wang LS, Rocha CM, Larue B, Henry C, McIntyre CM, Riedl KM, Schwartz SJ, Stoner GD. 2010. Drinking water with red beetroot food color antagonizes 
esophageal carcinogenesis in N-nitrosomethylbenzylamine-treated rats. J Med Food 13:733-739.

Lowry OH, Rosebrough NJ, Farr AL, Randall RJ. 1951. Protein measurement with the folin phenol reagent. J Biol Chem 193:265-275.

Mohankumar K, Pajaniradje S, Sridharan S, Singh VK, Ronsard L, Banerjea AC, Benson CS, Coumar MS, Rajagopalan R. 2014. Mechanism of apoptotic induction in human breast cancer cell, MCF-7, by an analog of curcumin in comparison with curcumin--an in vitro and in silico approach. Chem Biol Interact 210:51-63.

Paluszczak J, Krajka-Kuzniak V, Baer-Dubowska W. 2010. The effect of dietary polyphenols on the epigenetic regulation of gene expression in MCF7 breast cancer cells. Toxicol Letters 192:119-125.

Pervaiz A, Zepp M, Adwan H, Berger MR. 2015. Riproximin modulates multiple signaling cascades leading to cytostatic and apoptotic effects in human breast cancer cells. J Cancer Res Clin Oncol DOI 10.1007/s00432-015-2013-3.

Rao B, Lain S, Thompson AM. 2013. P53-based cyclotherapy: exploiting the 'guardian of the genome' to protect normal cells from cytotoxic therapy. Br J Cancer 109:29542958. 
Reddy KM, Alexander-Lindo RL, Nair MG. 2005. Relative inhibition of lipid peroxidation, cyclooxygenase enzymes, and human tumor cell proliferation by natural food colors. J Agric Food Chem 53:9268-9273.

Rodrigues NR, Rowan A, Smith ME, Kerr IB, Bodmer WF, Gannon JV, Lane DP. 1990. p53 mutations in colorectal cancer. Proc Natl Acad Sci USA 87:7555-7559.

Sreekanth D, Arunasree MK, Roy KR, Reddy C, Reddy GV, Reddanna P. 2007. Betanin a betacyanin pigment purified from fruits of Opunita ficus-indica induces apoptosis in human chronic myeloid leukemia cell line K562. Phytomedicine 14:739746.

Stintzing FC, Schieber A, Carle R. 2002. Identification of betalains from yellow beet (Beta vulgaris L.) and cactus pear [Opuntia ficus-indica (L.) Mill.] by high-performance liquid chromatography-electrospray ionization mass spectrometry. J Agric Food Chem 50:2302-2307.

Stintzing FC, Conrad J, Klaiber I, Beifuss U, Carle R. 2004. Structural investigations on betacyanin pigments by LC NMR and 2D NMR spectroscopy. Phytochemistry 65:415422.

Tesoriere L, Allegra M, Butera D, Livrea MA. 2004. Absorption, excretion, and distribution of dietary antioxidant betalains in LDLs: potential health effects of betalains in humans. Am J Clin Nutr 80:941-945. 
Tesoriere L, Gentile C, Angileri F, Attanzio A, Tutone M, Allegra M, Livrea MA. 2013. Trans-epithelial transport of the betalain pigments indicaxanthin and betanin across Caco-2 cell monolayers and influence of food matrix. Eur J Nutr 52:1077-1087.

van Oijen MG, Slootweg PJ. 2000. Gain-of-function mutations in the tumor suppressor gene p53. Clin Cancer Res 6:2138-2145.

Velzenberger E, Vayssade M, Legeay G, Nagel MD. 2008. Study of cell behaviour on a cellulose anti-adhesive substratum. Cellulose 15: 347-357.

Von Elbe. 2001. Betalains. In Currents Protocols in Food Analytical Chemistry, F 3.1.1F3.1.7.

Zhang Q, Pan J, Wang Y, Lubet R, You M. 2013. Beetroot red (betanin) inhibits vinyl carbamate- and benzo(a)pyrene-induced lung tumorigenesis through apoptosis. Mol Carcinog 52:686-691.

Zhang X, Chen LX, Ouyang L, Cheng Y, Liu B. 2012. Plant natural compounds: targeting pathways of autophagy as anti-cancer therapeutic agents. Cell Prolif 45:466476. 


\section{Tables}

Table 1: Cell cycle distribution of cells grown on tPS or polyHEMA in the presence or absence (Control) of betanin/isobetanin extract.

\begin{tabular}{ccccc}
\hline & & Control & Bet./IsoBet. $(30 \mu \mathrm{M})$ \\
\hline MCF7 & 2D & G1 & $54.7 \% \pm 1.6$ & $49.1 \% \pm 4.2^{*}$ \\
& & $\mathrm{~S}$ & $26.4 \% \pm 2.8$ & $34.2 \% \pm 9.8$ \\
& & $\mathrm{G} 2 / \mathrm{M}$ & $18.8 \% \pm 4.1$ & $16.7 \% \pm 5.5$ \\
\cline { 2 - 5 } & 3D & $\mathrm{G} 1$ & $77.0 \% \pm 2.6$ & $68.2 \% \pm 1.8^{* *}$ \\
& & $\mathrm{~S}$ & $12.4 \% \pm 3.2$ & $17.8 \% \pm 2.2$ \\
& & $\mathrm{G} 2 / \mathrm{M}$ & $10.6 \% \pm 0.7$ & $14.0 \% \pm 0.7 * *$ \\
\hline MDA-MB231 & 2D & $\mathrm{G} 1$ & $62.3 \% \pm 1.9$ & $67.4 \% \pm 1.2$ \\
& & $\mathrm{~S}$ & $24.8 \% \pm 1.6$ & $19.8 \% \pm 0.9 *$ \\
& & $\mathrm{G} 2 / \mathrm{M}$ & $12.9 \% \pm 0.8$ & $13.5 \% \pm 2.2$ \\
\cline { 2 - 5 } HDV & $\mathrm{G} 1$ & $74.6 \% \pm 10.0$ & $72.4 \% \pm 10.5$ \\
& & $\mathrm{~S}$ & $22.9 \% \pm 11.6$ & $21.7 \% \pm 13.2$ \\
& & $\mathrm{G} 2 / \mathrm{M}$ & $2.5 \% \pm 2.9$ & $5.8 \% \pm 2.7$ \\
\hline & 2D & $\mathrm{G} 1$ & $51.2 \% \pm 2.4$ & $58.4 \% \pm 1.9$ \\
& & $\mathrm{~S}$ & $40.0 \% \pm 1.5$ & $30.2 \% \pm 2.5^{*}$ \\
& & $\mathrm{G} 2 / \mathrm{M}$ & $8.8 \% \pm 1.4$ & $11.7 \% \pm 1.6^{*}$ \\
\cline { 2 - 4 } & 3D & $\mathrm{G} 1$ & $90.1 \% \pm 1.4$ & $80.9 \% \pm 4.5^{*}$ \\
& & $\mathrm{~S}$ & $5.5 \% \pm 1.2$ & $13.1 \% \pm 4.6$ \\
& & $\mathrm{G} 2 / \mathrm{M}$ & $4.3 \% \pm 1.3$ & $5.9 \% \pm 1.2$ \\
\hline
\end{tabular}

Results are means \pm SD of three experiments each performed in triplicate. Asterisks indicate significant differences in cell cycle distribution of treated and control cells (Dunn test): *, $\mathrm{p}<0.05 ; * *, \mathrm{p}<0.01 ; * * *, \mathrm{p}<0.001$. 
Table 2: Annexin V labeling of MCF-7, MDA-MB231 and HUVEC cells treated with betanin/isobetanin or staurosporine.

\begin{tabular}{rcccc}
\hline & & Control & Bet./IsoBet. $(30 \mu \mathrm{M})$ & Staurosporine $(1 \mu \mathrm{M})$ \\
\hline MCF7 & 2D & $0.59 \% \pm 1.41$ & $23.24 \% \pm 2.72 *$ & $18.75 \% \pm 11.19 *$ \\
& 3D & $11.0 \% \pm 6.91$ & $17.29 \% \pm 6.25$ & $29.41 \% \pm 14.51 *$ \\
\hline MDA-MB231 & 2D & $0.29 \% \pm 0.04$ & $0.71 \% \pm 0.15$ & $13.45 \% \pm 2.52 * * *$ \\
& 3D & $1.94 \% \pm 0.5$ & $4.25 \% \pm 1.40^{*}$ & $1.79 \% \pm 0.68$ \\
\hline HUVEC & 2D & $1.44 \% \pm 0.72$ & $4.05 \% \pm 0.86$ & $56.99 \% \pm 10.37 * * *$ \\
& 3D & $25.06 \% \pm 5.62$ & $38.72 \% \pm 7.8$ & $18.13 \% \pm 7.81$ \\
\hline
\end{tabular}

Results are means \pm SD of two experiments each performed in triplicate. Asterisks indicate significant differences in Annexine-V labelling of treated and control cells (Dunn test): *, $\mathrm{p}<0.05 ; * * * \mathrm{p}<0.001$. 